appearing on a programme live or to insist, as you suggest, that programmes should have some sort of informed monitoring before they are shown.

Dan Tunstall Pedoe

Department of Cardiology,

St Bartholomew
London EC1

\section{Confidentiality of medical records}

SIR,-Your legal correspondent (8 July, p 135) refers to a recent ruling on appeal to the House of Lords about the entitlement of patients engaged in litigation to receive copies of their hospital medical records. Concern had already been expressed at this ruling when it was discussed at a recent meeting of the Joint Medicolegal Subcommittee of the Joint Consultants Committee and the Central Committee for Hospital Medical Services of the BMA.

The case of McIvor $v$ Southern Health and Social Services Board (NI) was the subject of the appeal to the House of Lords and the ruling established that the normal procedure in cases of litigation whereby patients' confidential records may be passed in confidence to a medical adviser appointed by the plaintiff or his solicitor was not in law justified. While acknowledging that it might not be always in the interests of the patient that he should have access to notes on his own case, the decision of the House of Lords was that patients or their legal advisers could in appropriate circumstances and by due process have access to the patients' medical records.

We know that some health authorities have already interpreted this decision as meaning that patients or their legal advisers must be given access to their clinical records on application. This is not the case. The defence societies are now consulting the Health Departments about this judgment and will be issuing advice to their respective members. Meanwhile I hope that the contents of this letter will provide some help and reassurance to doctors. The most important point to stress-to colleagues and to administratorsis that the House of Lords decision does not create a precedent whereby clinical records must automatically be released to patients : it has established that relevant records can be ordered to be released, but only if the application for such release is justifiable before the High Court. Any doctor who is involved in a case involving access to medical records is advised to consult the British Medical Association or his medical defence society.

E GREy-TURner

Secretary,
British Medical Association

BMA House,

SIR,-Perhaps the most effective way of maintaining the confidentiality of a patient's medical record would be for the patient (or, if a child, his parent) to keep it. Such a system is used for children in developing countries and if, as Miss Kathleen Shaw says (15 July, p 191), some pregnant women are allowed to carry their case notes around their locality they might just as well keep them altogether. It would mean that doctors would have to be careful about what they write in them, but this would be no bad thing: case notes often tell quite as much about the writers of them as they do about the patient. The purpose of the individual medical record is to act as an aid to memory and clear thinking. Any value it may have for subsequent research does not depend upon its remaining in the writer's possession. It is not, as Professor Richard Beard implies in the same article, a necessary method of communication between doctors about a particular patient but without the latter's participation. This is better done by personal contact-by telephone or preferably by talking face to face. The modern practice of "referral" is a poor substitute for the older practice of "consultation."

The practice of circulating copies of specialists' reports to other medical authorities than the referring doctor is not confined to paediatrics, Dr A B David (1 July, p 56). It has also happened in psychiatry within my experience and this raises similar ethical problems. I have known a lay member of a hospital management committee to read a patient's notes without medical authorisation; and of course intelligent patients will often read their own notes if they get the opportunity. As a result I have learnt to write in case notes only things which I am prepared for anyone else to read.

If people were encouraged to keep their own records no doubt some few would lose them and some fewer might falsify them; but for most people, being trusted to act responsibly would be the best way of learning to act responsibly. It is essential that doctors should make records, but the reasons why it should be medical men or institutions which maintain possession of them need reexamination. Our present practice is expensive and inefficient and breeds mistrust. It extends our power over patients in a way we do not need and ought not to have.

Hay-on-Wye,

JAMES MATHERS ${ }^{1}$ Morley, D, Pediatric Priorities in the Developing
World, pp 148 et seq. London, Butterworths, 1973.

SIR,-I was interested by Dr A O Staines's letter (15 July, p 206) about confidentiality of children's medical records. His local paediatric department told him that parents consent is always asked for before passing on information to others. Unfortunately this rule is certainly not followed elsewhere.

Not long ago I took one of my children to see a local paediatrician and was amazed when, a few days later, a non-medical person from the town hall rang me up, told me that she had a copy of the paediatrician's letter to the general practitioner, and asked for the name of the school to which the information contained in it could be sent.

In my view it should be an invariable rule that parents are asked for their agreement before any information obtained at a consultation is passed on to non-medical people. Sadly, there is far, far too much disregard of the principle of confidentiality these days.

David Delvin

Bromley, Kent

\section{Help for parents of the handicapped}

SIR,-Mr Colin Appleton (20 May, p 1348) emphasises that many parents of handicapped children would welcome a written report of their child's condition. This has prompted us to report our experience of * writing letters to parents at the end of a child's period of assessment in the child development centre at this hospital. We are indebted to Miss Rosemary Evans and to Professor John and Dr Elizabeth Newson of Nottingham University for introducing us to this idea.

After the case conference, which is attended by parents, we prepare a discharge summary in the usual way, but the last sectiondiagnosis and management-is written with the top copy as a letter to the parents. With their permission copies of this are sent to individuals to whom it would be inappropriate to send the full medical summary. This is an ideal way of re-explaining difficult concepts, putting into perspective the various components of a complex problem such as language delay or autism, and helping to establish the balance between optimism and realism. Goals and limitations of treatment are noted and, if relevant, genetic aspects are discussed.

By. sending copies of this letter to the health visitor, social worker, etc, their work is simplified and made more productive. In educational problems communication between parents and teachers can often be smoothed when the viewpoints of each are summarised in a letter. Possibly the greatest advantage is that all the professionals involved with the child know exactly what the parents have been told.

The preparation of these letters is initially time-consuming, but speed comes with practice. The content and vocabulary must be tailored to the education and background of the parents. It is not easy to discuss emotional and behaviour problems in writing and to ensure that this is done in a constructive rather than in a critical way. Possible medicolegal risks have been raised, but one is expressing considered opinions already recorded in the medical notes and therefore this risk is minimal.

DAVID M HALI HUGH JOLLY

Department of Paediatrics,

Charing Cross Hospital,

London W6

\section{Snakes and snake bite}

SIR,-My review of Snakes and Snakebite by John Visser and David S Chapman (13 May, p 1269) has provoked comments from two correspondents (15 July, p 203).

In reply to $\mathrm{Mr} \mathrm{J}-\mathrm{J}$ Brossy, the dangers of pressure-relieving fasciotomies after snake bite include bleeding prolonged by venom-induced coagulopathy, secondary infection, delayed recovery, and damage to nerves and vessels. Sites such as the anterior tibial compartment and digital pulp space ${ }^{1}$ may create special problems, but in the experience of a number of clinicians, ${ }^{23}$ including Professor Chapman and myself, fasciotomy has never proved necessary in patients given adequate medical treatment. The use of tourniquets in human victims of snake bite remains controversial because of the lack of direct evidence. Animal experiments suggest, however, that tight (arterial) tourniquets might delay fatal envenoming following elapid bites, ${ }^{45}$ allowing the patient to reach hospital alive. There is evidence that specific antivenom prevents local necrosis if given intravenously within six hours of a puff adder bite. ${ }^{6}$ Antivenoms have been shown to counteract other local effects of venoms. ${ }^{5}$ The indications for antivenom were mentioned in my review. 